\title{
Interleukin 1 beta, hand and foot bone mineral content and the development of joint erosions in rheumatoid arthritis
}

\author{
J North, R D Situnayake, M Tikly, A Cremona, J Nicoll, D S Kumararatne, G Nuki
}

\begin{abstract}
Objective-To assess the relationship between plasma levels of the cytokine interleukin-1 beta (IL-1 beta) and the progression of rheumatoid arthritis (RA). Methods-Two subgroups of patients, one with persistently raised ESR $(>/=50 \mathrm{~mm} /$ hour, $n=16$, group $A)$ and one with persistently low ESR $(</=28 \mathrm{~mm} / \mathrm{hour})$, $n=18$, group I) were chosen to represent stable extremes of inflammatory activity from a prospective study of 106 patients with active RA studied over one year in a single centre. The change from baseline in hand, foot and calcaneal bone mineral content measured by single photon absorptiometry and radiographic score of joint damage was measured over 12 months, together with plasma IL-1 beta and erythrocyte sedimentation rate.
\end{abstract}

Results-Significant progression of joint damage occurred in both subgroups over one year $(p<0.0001$, paired $t$ test) though progression was significantly less in the subgroup with low ESR $(p<0.05$, ANOVA). Hand and foot bone mineral content decreased by almost $10 \%$ in the subgroup with raised ESR ( $<<0.005$, paired $t$ test). Stepwise linear regression analysis revealed significant independent relationships between radiographic progression over one year and plasma IL-1 beta and ESR (multiple R 0.674, F = 11.64, p < 0.0002). No such relationships were observed for changes in bone mineral content parameters.

Conclusions-Plasma IL-1 beta levels correlate weakly with progression of joint damage though not with loss of peripheral bone density in RA. A significant reduction in peripheral bone mineral content occurs over one year in patients with active $R A$ with persistently raised ESR.

(Ann Rheum Dis 1994; 53: 543-546)

Cartilage and bone resorption are typical features of early rheumatoid arthritis which are traditionally recognised by the radiological signs of joint space narrowing, periarticular osteoporosis and marginal joint erosions. Using single photon absorbtiometry, studies of hand and foot bone mineral content in patients with rheumatoid arthritis (RA) have shown that peripheral bone density is reduced in RA. ${ }^{12}$ These findings might indicate that the catabolic process occurring within the joint might also occur in periarticular bone. The cytokine IL-1 beta is a potential mediator of this process. It possesses many relevant biological properties which include activation of the proteases collagenase and stromelysin, inhibition of collagen and proteoglycan synthesis and stimulation of osteoclastic bone resorption. ${ }^{3}$ It is detectable in synovial fluid from patients with RA and plasma levels correlate weakly with parameters of disease activity such as pain, joint tenderness and the erythrocyte sedimentation rate. ${ }^{4}$ To test the hypothesis that interleukin 1 beta is involved in the progression of erosive joint disease and periarticular bone loss in RA, we have studied plasma IL-1 beta, peripheral bone mineral content and a radiological index of joint damage prospectively over one year, in patients with active RA.

\section{Methods}

All patients were recruited for study at a single centre and fulfilled the 1987 ACR criteria for RA. All had disease of less than eight years duration and were selected on the basis of at least two of the following features to define a population with active disease; early morning stiffness $>45$ minutes, swelling of three or more joints, Ritchie articular Index ${ }^{5}>9$ and ESR $>28 \mathrm{~mm} /$ hour. A total of 106 patients were recruited and the clinical parameters were studied at 0,6 and 12 months. In addition, hands and feet were radiographed at each visit using industrial fine grain film. Joint damage of the hands and feet was assessed by two observers (MT, RDS), 'blind' to patient identity, using Larsen's technique, and aided by standard reference films ${ }^{6}$; an increasing score (total Larsen score, the sum of hand and foot measurements) denoted increasing radiological damage. The left hand and foot were scanned using the $I^{125}$ single photon absorptiometry technique described elsewhere and bone mineral content in grams was calculated. At the calcaneum, reflecting trabecular bone remote from the joint, bone mineral density was calculated $\left(\mathrm{gr} / \mathrm{cm}^{2}\right)$. Coefficients of variation were $1 \cdot 9 \%, 2 \cdot 8 \%$ and $4 \cdot 2 \%$ respectively for hand, foot and calcaneal measurements. The changes over one year for Larsen score and bone density measurements were also computed. 
Table 1 Details of therapy at entry and one year for groups $A$ and $I$

\begin{tabular}{lllllll}
\hline Group & $\begin{array}{l}\text { O months } \\
\text { DMARD }\end{array}$ & No DMARD & Steroid & DMARD & No DMARD & Steroid $^{\star}$ \\
\hline Group A & 13 & 3 & 2 & 12 & 4 & 3 \\
Group I & 10 & 8 & 2 & 14 & 4 & 1 \\
\hline
\end{tabular}

^Prednisolone dose no greater than $10 \mathrm{mg}$.

Though all patients by definition fulfilled the criteria for active disease at entry, two subgroups of patients from the original cohort of 106 patients were chosen to represent stable extremes of inflammatory activity by selecting on the basis of a persistently elevated ESR $(>/=50 \mathrm{~mm} /$ hour $)$ at 0,6 and 12 months (group A, 16 patients) or a persistently low ESR $(</=28 \mathrm{~mm} /$ hour, group I, 18 patients) at these time points. Details of therapy for these patients are shown in table 1 .

Stored aprotinin treated plasma samples taken at 0 and 12 months from these patients were assayed for IL-1 beta using a commercial ELISA ('Cistron' IL-1 beta ELISA, Lab Impex, United Kingdom) after chloroform extraction, as previously described. ${ }^{4}$ All assays were performed on coded samples in duplicate in a separate laboratory ( $\mathrm{LN}, \mathrm{RDS}$ ).

Changes in hand and foot bone mineral content, calcaneal bone mineral density and Larsen score over one year were related to initial and mean values for ESR and IL-1 beta using stepwise logistic linear regression analysis. This technique is used to assess the ability of independent variables (initial and mean values for ESR and IL-1) both in combination and individually to explain variation in the dependent variables (change in radiological and bone mineral content parameters over one year). Student's $t$ test was used to compare paired data and analysis of variance was used for non-paired data. All statistics were performed using the statistical package Dbstats and Microsoft Excel 5·0.

\section{Results}

The mean(SD) age of the parent population of 106 patients was $54(11 \cdot 1)$ years (range $26-84$ years) and mean disease duration 38 months (range 4-96 months). Details of the two subgroups of patients selected for cytokine assays are shown in table 2 . Disease activity remained stable in the two groups over the period of study and differed considerably as expected with respect to ESR. There were no statistically significant differences for Ritchie Articular Index or duration of early morning stiffness between the two subgroups at any time point.

The total Larsen score of joint damage and hand (HBMC), foot (FBMC) and calcaneal (CBMD) bone mineral content measurements are shown in table 2. Significant progression of joint damage occurred in both groups over one year ( $\mathrm{p}<0.0001$, paired $t$ test). The mean group A increase was $21.7 \%$ and group I increase $17 \cdot 7 \%(p<0 \cdot 05$, ANOVA). HBMC and FBMC fell significantly by 12 months only in group $\mathrm{A}(\mathrm{p}<0.005$, paired $t$ test; HBMC mean decrease $9 \cdot 76 \%$, FBMC mean decrease $9.63 \%$ ) and not in group I (HBMC mean decrease $6 \cdot 3 \%$, FBMC mean decrease $2 \cdot 7 \%$, NS). The change in FBMC (but not HBMC) was significantly greater over 12 months in group A compared with group I $(p<0.05$ ANOVA). Calcaneal bone mineral density did not change significantly in either group (group A mean-2.43\%, group I mean $0 \%$ ).

Between group comparisons at month 0 revealed that total Larsen score was significantly greater in group A (table $3, F=4.53$, $\mathrm{p}<0.05$, ANOVA), but the differences between groups observed for bone mineral content parameters did not reach statistical significance. By 12 months the differences between groups reached significance for total Larsen score, HBMC and FBMC (table 3, $\mathrm{p}<0.05)$ but not for CBMD.

Using stepwise logistic linear regression analysis a significant relationship between change in total Larsen score over one year and plasma IL- 1 beta and ESR at visit 1 was observed (multiple $\mathrm{R} \quad 0.674, \mathrm{~F}=11.64$, $\mathrm{p}<0 \cdot 0002)$. Significant independent contributions to the regression model were made by IL-1 beta at visit $1(\mathrm{~T}=3.22, \mathrm{p}<0.0035)$ and ESR at visit $1(T=2 \cdot 82, \mathrm{p}<0 \cdot 0088)$. No such relationships were observed for changes in

Table 2 Clinical and laboratory data of subgroups of $R A$ patients in whom plasma IL-1 beta measurements were made

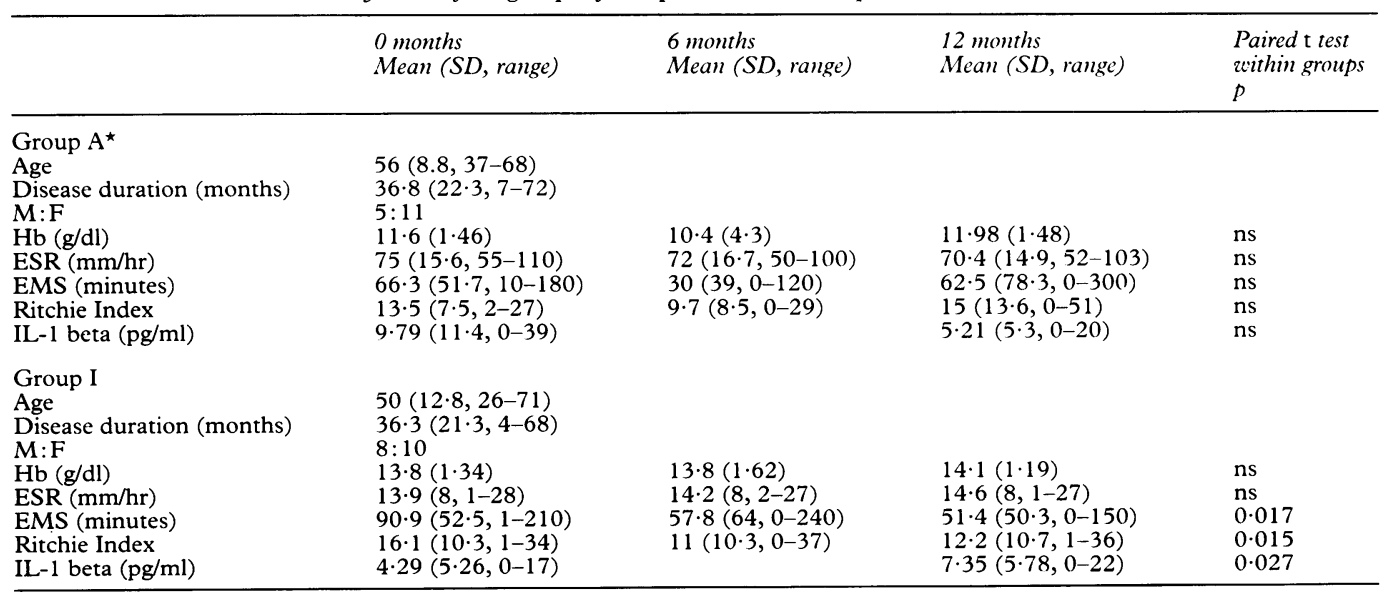

EMS duration of morning stiffness.

*There were no statistically significant differences between groups A and I with respect to EMS, Ritchie Index or IL-1 beta (analysis of variance) 
Table 3 Radiological damage (Larsen score), hand, foot and calcaneal bone mineral content in rheumatoid arthritis patients with $E S R>/=50 \mathrm{~mm} / \mathrm{hour}$ (group A) and ESR $</=28 \mathrm{~mm} /$ hour for 12 months (group I)

\begin{tabular}{|c|c|c|c|c|c|c|c|c|}
\hline & $\begin{array}{l}0 \text { months } \\
\text { Mean }(S D)\end{array}$ & & & & $\begin{array}{l}12 \text { months } \\
\text { Mean (SD) }\end{array}$ & $T$ & & $\begin{array}{l}\text { Paired t test } \\
p\end{array}$ \\
\hline $\begin{array}{l}\text { Group A }(\mathrm{n}=16) \\
\text { Total Larsen Score } \\
\text { HBMC }(\mathrm{g}) \\
\text { FBMC }(\mathrm{g}) \\
\text { CBMD }\left(\mathrm{g} / \mathrm{cm}^{2}\right)\end{array}$ & $\begin{array}{l}62 \cdot 5(30 \cdot 2) \\
16 \cdot 48(6 \cdot 73) \\
29 \cdot 42(10 \cdot 3) \\
0.397(0 \cdot 21)\end{array}$ & & & & $\begin{array}{l}76 \cdot 7(31.97) \\
14 \cdot 85(6.57) \\
25 \cdot 7(12 \cdot 2) \\
0.376(0 \cdot 25)\end{array}$ & $\begin{array}{l}5 \cdot 17 \\
3 \cdot 61 \\
3 \cdot 28 \\
1 \cdot 03\end{array}$ & & $\begin{array}{l}0.0001 \\
0 \cdot 003 \\
0 \cdot 005 \\
\text { ns }\end{array}$ \\
\hline $\begin{array}{l}\text { Group I }(\mathrm{n}=18) \\
\text { Total Larsen Score } \\
\text { HBMC }(\mathrm{g}) \\
\text { FBMC }(\mathrm{g}) \\
\text { CBMD }\left(\mathrm{g} / \mathrm{cm}^{2}\right)\end{array}$ & $\begin{array}{l}46 \cdot 4(20 \cdot 4) \\
20 \cdot 7(5 \cdot 17) \\
35 \cdot 9(9 \cdot 8) \\
0.441(0.098)\end{array}$ & & & & $\begin{array}{l}54 \cdot 6(21 \cdot 3) \\
19 \cdot 4(4 \cdot 52) \\
35(9 \cdot 1) \\
0 \cdot 444(0 \cdot 090)\end{array}$ & $\begin{array}{l}6 \cdot 86 \\
1 \cdot 78 \\
1 \cdot 80 \\
0 \cdot 26\end{array}$ & & $\begin{array}{l}0 \cdot 0001 \\
\text { ns } \\
\text { ns } \\
\text { ns }\end{array}$ \\
\hline $\begin{array}{l}\text { Between group } \\
\text { Analysis (Anova) } \\
\text { F } \\
\text { P }\end{array}$ & $\begin{array}{l}\text { Total } \\
\text { Larsen Score } \\
4.53 \\
0.041\end{array}$ & $\begin{array}{l}\text { HBMC } \\
2.56 \\
0.12\end{array}$ & $\begin{array}{l}\text { FBMC } \\
1 \cdot 88 \\
0 \cdot 18\end{array}$ & $\begin{array}{l}\text { CBMD } \\
0 \cdot 11 \\
0.74\end{array}$ & $\begin{array}{l}\text { Total } \\
\text { Larsen Score } \\
5 \cdot 63 \\
0.024\end{array}$ & $\begin{array}{l}\text { HBMC } \\
5 \cdot 11 \\
0.031\end{array}$ & $\begin{array}{l}\text { FBMC } \\
4.9 \\
0.035\end{array}$ & $\begin{array}{l}\text { CBMD } \\
0.58 \\
0 \cdot 45\end{array}$ \\
\hline
\end{tabular}

$\mathrm{HBMC}=$ Hand bone mineral content $\mathrm{FBMC}=$ foot bone mineral content $\mathrm{CBMD}=$ calcaneal bone mineral density

bone mineral content parameters. When the change in Larsen scores for hand and feet were analysed separately by multiple stepwise logistic linear regression analysis, the change in Larsen score for the hand correlated with mean ESR and plasma IL-1 beta at visit 1 (multiple $\mathrm{R} 0.659, \mathrm{~F}=11.89, \mathrm{p}<0.0001)$ and the change in Larsen score in the foot correlated only with plasma IL-1 beta at visit 1 (multiple $\mathrm{R} 0.426, \mathrm{~F}=6.86, \mathrm{p}<0.02)$.

\section{Discussion}

Periarticular osteoporosis, joint space narrowing and radiological erosions are important early features of severe RA which are often used to measure disease progression using the Larsen score. ${ }^{6}$ Using single photon absorptiometry, a measure of periarticular bone mineral content may be obtained. ${ }^{7}$

The present prospective study was designed to test the hypothesis that plasma IL-1 beta levels might correlate with erosive joint damage and periarticular bone loss in RA by utilising single photon absorptiometry to measure changes in peripheral bone mineral content and Larsen's technique to assess radiographic progression of the disease. The patients were selected from a cohort of 106 patients with active RA to represent stable extremes of inflammatory activity determined by ESR as a marker of the acute phase response. This served to minimise the confounding effect of disease suppressive therapy and spontaneous disease fluctuations. The treatment of both groups with respect to disease modifying and steroid therapy were broadly similar (table 1) and there were no significant differences between the two groups with respect to duration of morning stiffness or Ritchie articular index (table 2). Plasma IL-1 beta measurements were performed using a commercial ELISA ('Cistron' IL-1 beta ELISA, Lab Impex, United Kingdom) after chloroform extraction as previously described, ${ }^{4}$ to remove inhibitors that may interfere with assays in serum. Using this technique a weak relationship between plasma IL-1 beta and measures of disease activity was observed in patients with RA, although in these studies no radiological or bone density assessments were made. ${ }^{4}$
The present study has demonstrated a significant relationship between plasma immunoreactive IL- 1 beta, ESR and the radiological progression of RA over 12 months using Larsen's technique. Although significant, the relationship we observed was weak. This could be explained by the effects of other (unmeasured) cytokines and/or the action of specific biological inhibitors of IL-1 beta. Examples would be the IL-1 receptor antagonist (IL-1 ra) which binds competitively to the same receptor without inducing a biological response ${ }^{8}$ and the shed IL-1 receptor itself. $^{9}$ Moreover, plasma IL-1 beta levels are unlikely to reflect synovial synthesis alone. Measurement of the ratio of plasma IL-1 beta to IL-1 ra may prove more valuable in future studies investigating the radiological progression of RA. No relationship was observed between plasma IL-1 beta levels and changes in appendicular bone mineral content. However, hand and foot bone mineral content decreased significantly by almost $10 \%$ in group A, with a persistently high ESR. The change in foot bone mineral content over one year was significantly greater in this subgroup than the group with persistently low ESR. Furthermore by 12 months the differences between groups reached significance for HBMC and FBMC (table 3, p < 0.05) but not for CBMD suggesting a link between peripheral bone loss and the acute phase response. The mechanism for the observed bone loss in RA is poorly understood. It may include the effect of active disease on mobility and the catabolic effect of cytokines such as interleukin- 1 beta, interleukin- 6 and tumour necrosis factor which are detectable in synovial effusions from patients with rheumatic diseases. $^{9}$ In animal experiments the intraarticular injection of IL-1 beta induces joint swelling, cartilage loss and the development of bony changes resembling RA, ${ }^{10}$ supporting a role for IL-1 beta as a mediator of the erosive changes and periarticular bone loss observed in RA.

Our study did not show a relationship between plasma IL-1 beta levels and peripheral bone loss but the (weak) correlation observed with radiological progression in patients with RA suggests a role for IL-1 beta as one of the mediators of this process. 
1 Tikly M, Nicoll J J, Pve D, et al. Prospective study of hand, foot and calcaneal bone minereal in rheumatoid arthritis oot and calcaneal bone minereal in theumatoid arthritis using SPA. In: Christiansen C, Overgaard

2 Reid D M, Kennedy N S J, Nicoll J, Smith M A Tothill P, Nuki G. Total and peripheral bone mass in patients with psoriatic arthritis and rheumatoid arthritis. Clin Rheumatol 1986; 5: 372

3 Muegge K, Oppenheim JJ. Il-1 in autoimmunity. In: Talal N, ed. London: Academic Press, 1991: 153 76.

+ Eastgate J A. Symmons J, Wood N C, Grinlinto F M Di Giovine F S, Duff $G$ W. Correlation of plasma interleukin 1 levels with disease activity in rheumatoid arthritis. Lancet 1988; ii: $706-9$.

5 Ritchie D M, Boyle J A McInnes J M, et al. Clinical studies with an articular index for the assessment of joint tenderness in patients with rheumatoid arthritis. (of.lfed 978; 37: 393 406

6 Larsen A, Dale K, Dek M. Radiological eraluadion of

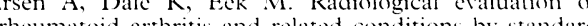

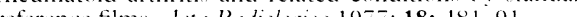

Nicoll JJ. Smith MA. Reid D, Ml. Measurement of hand icoll JJ, Smith MA, Reid D, at al. Measurement of han
bone mineral content using single photon absorptiometry. bone mineral content using single
Phw . Mid Biol 1987:32:697 706 .

8 Dinarello (.. Interleukin 1 and interleukin 1 antagonism. Blood 1901; 77 : 1627 52

9 Cope A P. Brennan F. il Crtokine measurements in biological fluids. $B r-7$ Rheumatol 1992; 31: 7214

10 Pettipher E R, Higgs ( $\mathrm{A}$. Interleukin 1 induces leucocyte infiltration and cartilage proteoglecan degradation in the snowial joint. Proc Nat Aiad Si LSA 1986; 83: $87+9=3$ 